\title{
VOZES DA AMAZÔNIA NA TRILHA DE SPIX E MARTIUS
}

\begin{abstract}
Willi Bolle ${ }^{1}$
Eckhard E. Kupfer ${ }^{2}$

Resumo: Por ocasião do bicentenário da viagem dos naturalistas alemães Spix e Martius pela Amazônia, os dois autores deste artigo, juntamente com dois cineastas, refizeram em 2019 o percurso daquela expedição. O principal objetivo foi estudar as continuidades e as mudanças ocorridas ao longo desses 200 anos. A viagem foi registrada num filme documentário do qual constam ao todo 23 entrevistas com habitantes da região: homens e mulheres, de todas as idades e representando uma ampla gama de profissões. São falas de trabalhadores braçais, um barqueiro, um colhedor e uma vendedora de produtos da selva, coordenadores de comunidades ribeirinhas, lideranças indígenas, narradores populares, professores, alunos, representantes de instituições culturais, gerentes de empresas e pesquisadores de várias disciplinas científicas. O registro documental deste conjunto de vozes de habitantes da Amazônia é feito com o objetivo de contribuir para a historiografia daquelas diversas atividades e dos saberes locais, e com isso, despertar um maior interesse para se conhecer a Amazônia e estimular a reflexão sobre os principais problemas dessa região atualmente.

Palavras-chave: Viagens e explorações científicas. Amazônia. Spix e Martius.
\end{abstract}

\section{VOICES FROM THE AMAZON ON THE SPIX AND MARTIUS TRAIL}

Abstract: On the occasion of the bicentenary of the journey of the German naturalists Spix and Martius through the Amazon, the two authors of this article, together with two filmmakers, retraced in 2019 the route of that expedition. The main objective was to study the continuities and changes that occurred over these 200 years. The trip has been recorded in a documentary film including 23 interviews with inhabitants of the region: men and women, of all ages and representing a wide range of professional activities. There are speeches by manual workers, a boatman, a harvester and a seller of products from the jungle, coordinators of riverside communities, indigenous leaders, popular narrators, teachers, students, representatives of cultural institutions, business managers and researchers from various scientific disciplines. The documentary register of this set of voices of inhabitants of the Amazon is made with the objective of contributing to the historiography of those diverse activities and of the local knowledge, and with that, arouse a greater interest to know the Amazon and stimulate reflection on the main problems of this region today.

Keywords: Scientific voyages and explorations. Amazon. Spix e Martius.

\section{VOCES DE LA AMAZONÍA EN EL CAMINO DE SPIX Y MARTIUS}

Resumen: Con motivo del bicentenario del viaje de los naturalistas alemanes Spix y Martius por el Amazonas, los dos autores de este artículo, junto con dos cineastas, volvieron en 2019 sobre el recorrido de esa expedición. El principal objetivo fue estudiar las continuidades y los cambios ocurridos a lo largo de estos 200 años. El viaje fue grabado en un documental con un total de 23 entrevistas a habitantes de la región: hombres y mujeres, de todas las edades y representantes de una amplia gama de profesiones. Hay discursos de obreros, un barquero, un recolector y una vendedora de productos de la selva, coordinadores de comunidades ribereñas, líderes indígenas, narradores populares, docentes, estudiantes, representantes de instituciones culturales,

\footnotetext{
${ }^{1}$ Professor titular sênior de literatura na Universidade de São Paulo.

${ }^{2}$ Diretor do Instituto Martius-Staden (São Paulo), de 2005 a 2020.
} 
empresarios e investigadores de diversas disciplinas científicas. El registro documental de este conjunto de voces de habitantes de la Amazonía se realiza con el objetivo de contribuir para la historiografía de esas diversas actividades y del conocimiento local, y con ello, despertar un mayor interés por conocer la Amazonía y estimular la reflexión sobre los principales problemas de esta región en la actualidad.

Palabras-llave: Viajes y exploraciones científicas. Amazonía. Spix y Martius.

\section{Introdução}

O relato Viagem pelo Brasil, 1817-1820, de Johann Baptist von Spix e Carl Friedrich Philipp von Martius, pode ser considerado o livro mais importante em língua alemã sobre o Brasil. O zoólogo Spix e o botânico Martius fizeram parte de uma comitiva de cientistas austríacos e alemães, que chegou no Brasil em julho de 1817, por ocasião do casamento da princesa Leopoldina de Habsburgo com o futuro imperador Dom Pedro I. Os dois naturalistas permaneceram no Brasil durante três anos. Depois de terem pesquisado a região Sudeste e os Sertões, eles viajaram pela Amazônia, de julho de 1819 até junho de 1820. Rememorando o bicentenário daquela viagem, os dois autores deste artigo, acompanhados de dois cineastas, refizeram a maior parte desse percurso, focalizando em 2019 a Amazônia.

Em que consiste a contribuição específica de Spix e Martius para o conhecimento da Amazônia? 1) O seu relato de viagem, inspirado no exemplo de Alexander von Humboldt, combina a apresentação de informações científicas com temas de interesse do público geral. 2) A escrita comunicativa e as gravuras que acompanham o texto (SPIX; MARTIUS, 1967), dão ao relato uma dimensão estética, que faz o leitor sentir os ambientes da natureza e da cultura local. 3) Com a coleta de dados etnográficos e linguísticos, os dois naturalistas tornaram-se precursores de etnólogos profissionais, como Karl von den Steinen, Theodor Koch-Grünberg e Curt Nimuendajú.

Ao refazer a viagem de Spix e Martius pela Amazônia, o nosso objetivo principal foi observar as continuidades e as mudanças ocorridas durante estes 200 anos. Para isso, foram importantes não apenas as observações geográficas e históricas, mas especialmente também as entrevistas que fizemos com habitantes da Amazônia nos vários pontos do nosso percurso. A palavra "trilha", no título deste artigo, é usada aqui num triplo sentido: 1) estamos seguindo o caminho dos dois viajantes, destacando quatro lugares principais e seus desdobramentos; 2) acompanhamos os seus campos temáticos - estudos da natureza, geografia física e humana, história, atividades econômicas, vida social, cultura cotidiana e costumes dos habitantes -, distanciando-nos, contudo, de sua visão 
eurocêntrica; 3) reproduzimos aqui as 23 entrevistas que foram inseridas no roteiro do nosso filme. ${ }^{3} \mathrm{O}$ registro documental deste conjunto de vozes de habitantes da Amazônia é feito com o objetivo de contribuir para a historiografia e estimular a reflexão sobre os principais problemas dessa região nos dias atuais.

\section{Primeira etapa da viagem: Belém e arredores}

A primeira etapa da viagem de Spix e Martius pela Amazônia foi a cidade de Belém. Localizada num ponto estratégico do delta do Amazonas, ela foi a porta de entrada para a colonização da região (AMARAL, 2004). Assim como os dois viajantes, iniciamos o nosso contato com Belém a partir de sua orla. Por um lado, permanecem as referências históricas antigas: o Forte do Castelo, que é o marco de fundação da cidade; a Catedral da Sé; e o Palácio Lauro Sodré, o antigo Palácio do Governo. Por outro lado, houve a partir dos anos 1960 uma acentuada verticalização arquitetônica da cidade. Um fato que foi registrado pelos viajantes, 200 anos atrás e que continua existindo é a extrema desigualdade social, como mostram os diferentes tipos de bairros e moradias.

A descrição, por Spix e Martius, da alimentação na Amazônia nos incentivou a observar as mercadorias na feira do Ver-o-Peso, que é o principal ícone da cidade de Belém. Todo dia, de madrugada, chegam barcos carregados de produtos do interior, que são postos à venda: peixes, mandioca - que é transformada em farinhas e em molho de tucupi -, frutas e castanhas. Além disso, é oferecida uma grande variedade de ervas medicinais. Sobre este tema fizemos a nossa primeira entrevista, com a experiente vendedora Socorro Loura:

Esta é uma garrafada para diabetes.

Aqui temos: jacareúba, carapanaúba, casca de mira-mira, jucá, casca de unha-degato, que dá muita quebra de irritação. A gente põe um jucá com eucalip.

Temos também a garrafada para reumatismo, que faz a massagem nas cadeiras, nas pernas.

Quando você tiver uma doença neste braço, o sr. não vai cuidar só desse braço aqui, vai passar também para o outro. Fazer massagem, e depois da massagem, fica fazendo assim, assim, para ficar bom. Aí, quando for na coluna, abaixa e passa nas pernas.

Depois, pula. Entendeu? Assim que é a massagem.

\footnotetext{
${ }^{3} \mathrm{O}$ documentário (48 minutos) com o título "Refazendo a viagem de Spix e Martius pela Amazônia", pode ser visto no website https://youtu.be/_eqyjKfd3z0. O roteiro é de W. Bolle e E. Kupfer; a filmagem e a montagem foram realizadas por Felipe Delfino e Gustavo Tonetti.
} 
Socorro Loura ganhou uma medalha. Tenho muito remédio. Eu vim de bisavó. Viu?

Durante os 200 anos que se passaram desde a viagem de Spix e Martius, ocorreram em Belém e em toda a Amazônia grandes mudanças históricas. Na década de 1830 aconteceu uma tentativa de revolução por parte dos habitantes das "cabanas": a Cabanagem (DI PAOLO, 1990). Ela foi brutalmente reprimida pelas forças da ordem. Em 1820, Spix e Martius fizeram o primeiro relato sobre a produção econômica de borracha na região. Entre 1850 e 1912, a Amazônia era a principal produtora e exportadora no mundo. $\mathrm{Na}$ época da borracha houve um forte aumento da população e uma significativa melhoria das cidades (SARGES, 2010). Mas, a partir de 1913, a produção de borracha da Amazônia foi superada pelos concorrentes da Ásia tropical. Começou, então, a época de declínio, que perdurou até a década de 1950. Esse período é o fundo histórico do romance Belém do Grão-Pará (1960), do escritor paraense Dalcídio Jurandir. Com a construção da rodovia Belém-Brasília e da Transamazônica, junto com os "Grandes Projetos" (mineração, agronegócio, barragens), começou, a partir dos anos 1960, um processo de modernização, que continua até os dias de hoje (CASTRO; MOURA; SÁ MAIA, 1995). Porém, como mostra a fisionomia atual de Belém, as grandes desigualdades sociais e os problemas de infraestrutura persistem.

Spix e Martius observaram também as manifestações da cultura popular, especialmente das tribos indígenas, com seus préstitos festivos. Essa tradição, misturada com elementos da cultura nordestina, continua viva nas encenações das festas juninas: nos desfiles, nos pássaros e no boi-bumbá (cf. MOURA, 1997). No bairro de Terra Firme, conversamos com Míriam, a coordenadora do grupo Boi Marronzinho, que nos explicou o ritual:

O boi-bumbá é um personagem do folclore brasileiro, que retrata a lenda que acontece numa fazenda entre o proprietário da fazenda e os funcionários. Uma das funcionárias deseja comer a língua do boi. Aí a história se desenvolve a partir desse desejo da mulher grávida. Aí eles acabam se apropriando do boi do patrão. E depois envolve o curandeiro com uso de ervas, para ressuscitar o boi e tornar o ambiente propício à realização de uma festa onde se desenvolve a dança do boibumbá. 
Nesse mesmo bairro da periferia, numa escola de ensino fundamental e médio, entrevistamos o professor Waldinei do Carmo de Souza: ${ }^{4}$

As periferias no geral são um tanto quanto marginalizadas pelo sistema. Porque o sistema vê a periferia como algo que incomoda eles.

Só que dentro das periferias da cidade de Belém tem o quê?

Tem gente que tem nome, sobrenome, tem cultura, tem força de vontade. É trabalhador.

E tem toda uma questão cultural que precisa ser explorada. Tem grupos que se reúnem para lutar contra uma cultura hegemônica. Tem, por exemplo, bois, tem quadrilhas.

Tem gente que estuda bastante, faz faculdade, luta no seu dia a dia.

Só que o próprio sistema nega tudo isso aí. Ele vê a questão da periferia como algo violento, algo incapaz.

Uma colega dele, a professora Rosineide Brandão, completou:

Eu trabalho em duas escolas, em duas esferas diferentes. Eu trabalho numa escola pública, a escola Dr. Celso Malcher, onde atuo há 12 anos, e trabalho numa escola particular, onde trabalho há 21 anos.

Mas eu percebo assim que há uma grande diferença entre as duas escolas.

A escola particular tem todo um aparato. O que você precisa na escola particular, você tem. As salas são climatizadas, você tem data-show, você tem um quadro bacana para trabalhar. Então, você tem muitos recursos.

A escola pública é uma escola que te dá um retorno maior. Os alunos são mais acolhedores. Os alunos topam qualquer desafio que nós queremos trabalhar com eles.

Para a ex-aluna Nayra Campos que, no final, estudou também numa escola particular, perguntamos: "Quais são, para uma aluna que estudou numa escola da periferia, as chances de ingressar na Universidade e no mercado de trabalho?" Ela respondeu:

As perspectivas de ingressar no mercado de trabalho e numa Universidade são complicadas, pela diferença de estruturas do ensino público e do ensino privado. Eu tinha livros, mas no ensino público, eu nunca tive livros. O ensino público não tem matéria de redação, que é muito importante para um vestibular. ${ }^{5}$

\footnotetext{
${ }^{4}$ Entre 2009 e 2014, o prof. W. Bolle realizou com um grupo de professores e alunos da Escola Estadual de Ensino Médio Dr. Celso Malcher, no bairro de Terra Firme, uma oficina de teatro com adaptações cênicas e montagens públicas dos cinco romances de Dalcídio Jurandir que têm como cenário a periferia de Belém. Essa experiência está detalhadamente descrita no livro Boca do Amazonas: sociedade e cultura em Dalcídio Jurandir, São Paulo: Edições do SESC, 2020.

${ }^{5}$ Em 2021 recebemos duas ótimas notícias sobre a continuação dos estudos de dois participantes da nossa oficina teatral: a ex-aluna Gabriela Gomes formou-se no Curso Superior Tecnológico em Radiologia; e o ex-aluno Gilvan Capela Jr. conseguiu ingressar no Curso de Teatro da UFPA.
} 
Da escola na periferia fomos para o Museu Goeldi, que é o mais antigo centro de pesquisas da natureza em Belém. Fomos conversar com a diretora, Ana Luiza Albernaz:

O Museu foi fundado em 1866, por Ferreira Pena. A principal intenção dele era que a gente desenvolvesse uma pesquisa nacional, porque na época a pesquisa era dominada pelos estrangeiros.

Hoje em dia o Museu tem uma coleção que não é a maior, mas a mais representativa, da Região Amazônica, a que contém mais tipos e a maior diversidade de plantas.

Ouvimos também o ex-diretor, Nelson Sanjad, autor de um livro sobre o Museu (cf. SANJAD, 2010):

A relação do Museu Goeldi com a obra de Spix e Martius é grande. No final do século 19, a obra de Martius e Spix já era uma referência para a comunidade científica.

A ideia de instalar aqui uma herma em homenagem a Spix e Martius remonta à década de 1890. Tem relação direta com a amizade entre Emílio Goeldi e Tereza da Baviera.

A herma foi doada pela Academia de Ciências da Baviera.

Ela foi inaugurada juntamente com o busto de Domingos Soares Ferreira Pena, que foi o fundador do Museu.

Ao caminhar pelo parque do Museu, pode se conhecer uma boa parte das plantas e dos animais típicos da Amazônia: palmeiras de açaí, castanheiras, vitórias-régias, tartarugas, lontras, jacarés, macacos e papagaios.

A exuberante natureza tropical, que Martius experimentou num sítio nos arredores de Belém, o inspirou a escrever um belo quadro da natureza. Vamos relembrar aqui algumas passagens:

Como me sinto feliz aqui! Diariamente mergulho na meditação do grande e indizível quadro da natureza, que me enche de deliciosas emoções.

Na madrugada, contemplo meus queridos amigos: árvores e arbustos em redor da casa; ah, vocês, perfumadas sebes de paulínias! No amanhecer aparecem reflexos róseos nas copas das castanheiras.

Ao meio-dia, o Sol brilha e o céu azul está risonho. Besouros dourados e beijaflores zumbem, borboletas e libélulas exibem um jogo de cores. E o jacaré na margem do rio deita-se na areia quente.

Com o crepúsculo da noite, plantas e animais são inspirados de novas expectativas. E o Éter, que envolve imenso a Terra, inspira humildade e confiança no coração do homem, após um dia de contemplação e prazer (SPIX; MARTIUS, 2017, vol. III, p. 18-22).

Nos arredores de Belém, visitados por Spix e Martius, escolhemos como exemplo a ilha do Combu. O principal produto cultivado ali é o açaí, um alimento típico de toda a 
região. Acompanhamos o caminho desse produto, da colheita até o consumo, e entrevistamos o ribeirinho seu Ladir, com 75 anos, que nos impressionou com sua habilidade de colher o açaí:

Com a idade de sete anos eu subi no açaizeiro para apanhar o açaí.

Eu cortei seringa também, porque era a única sobrevivência que havia. Era a seringa, o leite da seringa, dava muito dinheiro.

Também trabalhei muito com carvão. Era um trabalho escravo.

Hoje em dia é o açaí, é o mais vendável.

A natureza é uma benção de Deus. Ele está aqui me ajudando a cuidar dela.

Naquelas matas vimos um dos troncos imponentes da samaúma. Ali crescem também muitas árvores de cacau, a partir do qual se fabricam deliciosos chocolates, que estão à venda nesses locais.

O nosso barqueiro, Misael, falou sobre a sua vida como ribeirinho:

Como morador da ilha, ribeirinho aqui nascido e criado na ilha do Combu, é uma vida maravilhosa. Você tem tudo para sobreviver, não precisa mais quase nada, só o básico. Tudo o que a gente precisa, a gente tem aqui na Amazônia. Tem o açaí, tem o cacau. Então, na minha opinião, é uma vida maravilhosa.

Sou coordenador da comunidade da ilha do Combu.

Para o ribeirinho, hoje em dia, a fonte de renda é o açaí. As crianças têm uma escola de ensino fundamental, aqui na ilha, a Escola Bosque. O barquinho apanha as crianças todo dia às 6 e meia, leva à escola. Aí as crianças têm a merenda, saem às 11 e meia. E os de ensino médio, tem o próprio barco, que é pago pelo governo federal, que pega as crianças e leva para Belém.

Continuando no trajeto dos viajantes, deixamos Belém para trás e partimos para o interior. Passamos pelo Arquipélago do Marajó, ilha famosa pela criação de búfalos e que Martius chamou "a despensa da capital Belém". Depois da passagem pela cidade de Breves, chegamos no rio Amazonas, em cujas margens fica a vila-fortaleza de Gurupá, a partir de onde se controlava o acesso ao interior da Amazônia.

\section{Segunda etapa: Santarém e Óbidos}

Ao chegar na boca do rio Tapajós, de águas azuis, avistamos a orla de Santarém, a principal cidade no trajeto de Belém a Manaus. Nesse encontro de águas, Martius quase morreu afogado. Em agradecimento ao fato de ter sobrevivido, ele doou à cidade de Santarém um crucifixo, que está pendurado atrás do altar, na Igreja Matriz. Em Santarém, entrevistamos a pesquisadora Eloísa de Barros, que estuda o uso de remédios tradicionais e o trabalho de benzedeiras em comunidades quilombolas na região de Óbidos: 
A minha temática de estudo é a prática de benzeção e a produção de remédios medicinais, remédios naturais, que a gente chama de garrafadas.

São uma mistura de ervas, de cascas de árvores e de órgãos animais. A gente coloca tudo dentro de uma garrafa. Algumas misturam com cachaça, outras com vinho. Essas garrafadas são indicadas para diversos males.

Para a população que vive naquelas comunidades, é o primeiro recurso. Primeiro, elas vão com a benzedeira, só depois vão com o médico. Mas quando vão para o médico, elas retornam para a benzedeira. Então elas sempre falam, é o relato que a gente ouve: -- Eu vim aqui curar, porque com o médico não deu jeito. Então eu voltei aqui com você. ${ }^{6}$

O porto comercial de Santarém é um dos maiores da Amazônia. Os produtos a serem exportados, sobretudo grãos de soja, chegam do sul do Pará e de Mato Grosso pela BR-163. Muitos caminhões circulam diariamente por essa estrada, a chamada "Rodovia dos Grãos" (TORRES, 2005). Numa viagem que fizemos pela BR-163, de Santarém a Cuiabá, pudemos verificar a transformação da Floresta Amazônica em terras de agricultura e pastos de agropecuária. No estado de Mato Grosso, no trecho entre Guarantã do Norte e Sinop, a área desmatada já é maior que a da floresta preservada. Além do agronegócio, a região da BR-163 e o interior do Pará em geral são explorados também pela mineração. Entrevistamos a esse respeito o professor de geografia da UFPA e ambientalista João Márcio Palheta da Silva:

Os povos da Amazônia não sobrevivem da mineração, não sobrevivem do agronegócio. Eles sobrevivem da floresta. E para sobreviver da floresta, eles precisam que essa floresta fique em pé.

Ora, o modelo de desenvolvimento que temos hoje é pautado sobretudo no modelo do desmatamento. O Estado brasileiro deixou claro que o que interessa no Pará é a mineração.

A mineração é a commodity que gera o maior número de riqueza na nossa balança comercial.

Esse modelo é predatório para o desenvolvimento amazônico. Vai criar um problema muito grave entre a sobrevivência dos sujeitos que dependem da floresta e as grandes empresas que vêm para explorar. A tendência é acirrar esses conflitos, e nós teremos com certeza um caos ambiental e social na Amazônia.

Tudo isso são sinais de alerta de que o investimento no progresso do Brasil tem que ser pensado também em termos de responsabilidade ambiental e climática, como aliás já advertiram 200 anos atrás os naturalistas Spix e Martius.

De Santarém, continuamos subindo pelo rio Amazonas até chegar no seu lugar mais estreito. Nesse ponto estratégico foi erguido em 1697 o forte de Óbidos (REIS, 1979).

\footnotetext{
${ }^{6}$ Ver também o artigo de Eloísa Amorim de Barros e Augusto Rodrigues da Silva Jr (2020).
} 
Fomos conhecer o Forte, localizado acima do centro da cidade. Uma bateria complementar de canhões foi instalada nas proximidades, na Serra da Escama, em 1909. O nosso passeio por Óbidos nos levou da rua do Mercado Municipal até a Igreja Matriz. Em 1820, Spix e Martius encontraram Óbidos com um bom movimento comercial e um edificação razoável. Na Casa da Cultura entrevistamos o secretário da Cultura, o sr. Eduardo Dias:

Nós somos o berço da literatura da Amazônia. Nós temos dois escritores fundadores da Academia Brasileira de Letras. O escritor e crítico José Veríssimo e o romancista Inglês de Souza.

O Brasil não dá atenção para a Amazônia. Nós sempre estivemos à margem.

Atravessamos também o estreito de Óbidos. Na outra margem do rio, fica a comunidade de Trindade. De lá, se tem uma ótima vista do conjunto de Óbidos e da Serra da Escama.

Continuando a viagem, subimos o rio Amazonas em direção a Manaus. Em Óbidos e durante todo o percurso ao longo do rio Amazonas, sofremos, assim como os nossos viajantes, dos ataques de inúmeros insetos: mosquitos, mutucas, borrachudos, piuns e carapanãs. O contador de histórias Juraci Siqueira explica a origem dessa praga:

O seu Manoel Cardoso, caseiro do meu tio, contava que, quando Deus fez o mundo, ele precisou saber se o mundo estava completo de tudo. Procurou, então, uma senhora, uma velhinha, que estava ao pé do fogão a lenha. Deus se materializou para ela e perguntou:

-- Minha velha, o mundo está repleto, está completo de tudo?

Aí o contador, o Cardoso, remendou a velha e respondeu:

-- Está, sim, Senhor, só está faltando uns divertimentos.

-- Que divertimentos são esses, minha velha?

-- Mosca, carapanã, maruim...

Foi assim que nasceram as pragas.

Rumo a Manaus, passamos pela boca dos rios Nhamundá e Trombetas. Foi ali que ocorreu, em 1542, segundo o cronista Gaspar de Carvajal, a luta da tropa de Francisco de Orellana contra uma tribo de mulheres guerreiras, que os espanhóis chamaram de Amazonas (CARVAJAL, 1992). Martius, ao passar por esse local, em 1819, declarou categoricamente: "Não acredito na existência das Amazonas, nem no passado, nem no presente”. A guia Cristina Mota de Assis, que trabalha no Museu da cidade de Manaus, mas é de Oriximiná, à margem do Trombetas, esclareceu o assunto: 
Eu não acredito nas Amazonas, que é um mito europeu. Quais seriam os fundos de verdade que nós teríamos?

Eu acredito nas Ykamiabas. ${ }^{7}$

Ela explicou também o sentido dos muiraquitãs, as pedras mágicas usadas pelas mulheres guerreiras:

Elas davam esses amuletos aos homens em algumas festas, alguns rituais, em que o objetivo era a procriação. Davam um amuleto especial para homens que davam filhas mulheres. Com formato de sapo, com as pernas no formato de uma mulher tendo um parto.

\section{Terceira etapa: Manaus}

Chegamos no Encontro das Águas do Amazonas com o Rio Negro, e logo depois, na cidade de Manaus. Ela foi fundada em 1669 com o nome de Fortaleza de São José do Rio Negro; o primeiro núcleo populacional em torno do forte recebeu o nome de "Lugar da Barra" (FIGUEIREDO, 2011, p. 63-65). No Instituto Geográfico e Histórico encontrase uma maquete da fortaleza naquela época. Devido à sua localização estratégica, a vila tornou-se a capital e o centro do comércio da província de Rio Negro. Quando Spix e Martius visitaram a "Fortaleza da Barra", a população dessa vila era de apenas 3.000 habitantes; a da Manaus atual é de mais de 2 milhões.

No Centro Velho, no Museu da Cidade, estão expostos exemplos das principais mercadorias vendidas no Mercado Municipal. Destacam-se os produtos da floresta, como castanha-do-Pará, guaraná, cacau e cupuaçu. O porto de passageiros é muito movimentado. Daqui saem com grande frequência navios, barcos e lanchas para todos os quadrantes da Amazônia. O prédio antigo da Alfândega faz relembrar a época da borracha. No seu auge, foi inaugurado em 1896, o principal ícone de Manaus: o Teatro Amazonas (MONTEIRO, 2003).

Assim como no caso de Belém e das demais metrópoles do Brasil, também a fisionomia de Manaus é marcada por grandes diferenças sociais. A população mais pobre vive em palafitas, casas sobre estacas à beira do rio. Esses bairros com uma total ausência de infraestrutura são o correspondente das favelas no restante do país. A causa principal para o enorme crescimento da população de Manaus, a partir dos anos 1960, foi a criação da Zona Franca e a instauração do Distrito Industrial (KUPFER, 2010). Para a importação

\footnotetext{
${ }^{7}$ Ela nos fez conhecer o livro de Regina Melo, Ykamiabas: filhas da Lua, mulheres da Terra. Manaus: Ed. Travessia, 2006.
} 
e exportação dos produtos foi construído o porto de contêineres. O despachante Marcos Correa nos explicou essa mudança histórica:

Com o crescimento das indústrias da Zona Franca de Manaus, os portos e o aeroporto foram se modernizando também. O movimento das importações e das exportações também tem crescido a cada ano.

A SUFRAMA, que é a Superintendência da Zona Franca de Manaus, foi criada para que esta região tivesse um desenvolvimento. Geraram-se muitos empregos. Com isso, a população aumentou. Muitos vieram do interior para a cidade de Manaus. Assim houve também uma conservação muito grande da floresta.

A importância atual de Manaus no comércio nacional e internacional foi ilustrada com números pelo diretor da empresa Chibatão, o sr. Jhony Ramos:

Hoje, o porto de Manaus movimenta em torno de 20 mil contêineres por mês. 80 por cento do que entra em Manaus e sai de Manaus passa pelo porto de Chibatão. Atualmente a gente opera 15 navios por mês. São 7 navios de cabotagem, de cargas nacionais, E 8 navios que pegam carga no Panamá e trazem para Manaus. Geralmente matéria prima e outros produtos, para atender o comércio de Manaus. Hoje a gente pode dizer que tem em torno de 450 empresas no polo industrial de Manaus, que importam matéria prima, principalmente da Ásia. Produzem e distribuem o produto acabado ao longo do Brasil. Além de 950 comércios, que foram desenvolvidos durante esses 55 anos, na região de Manaus.

A cabotagem, hoje em dia, é vista como um recurso para reduzir o custo para a indústria. Hoje a cabotagem representa 70 por cento do volume de cargas que sai de Manaus e que vem para Manaus. É um custo menor, comparado com o transporte rodoviário-fluvial, e com mais segurança.

Um exemplo de preservação da floresta, nas imediações de Manaus, é o Jardim Botânico, que não foi plantado, mas criado com base na vegetação original. Entrevistamos o fundador e diretor do Jardim Botânico, Dr. Ennio Candotti:

Aqui, nesta Floresta, há muitos segredos a entender, a decifrar. Na Botânica ainda estamos como quando a Física ainda não conhecia a energia nuclear. Nós apenas classificamos. Não sabemos fazer uma folha. Nós precisamos de muita pesquisa básica, fundamental, na Amazônia.

$\mathrm{Na}$ área do Jardim Botânico está instalado também o MUSA, o Museu da Amazônia. Conseguimos marcar ali um encontro com duas lideranças indígenas. A cacique Socorro nos explicou como vive a sua comunidade, o povo Kokama:

Nosso lugar de refeição na comunidade indígena não chamamos cozinha. Na nossa linguagem do povo Kokama é casa de farinha. 
Nossa alimentação mais é peixe. Peixe diário, com farinha, macaxeira e panara, que é banana cozida. Nós, Kokama, gostamos muito de comer banana e macaxeira, com nossos peixes cozidos. Fazemos mujica de peixe.

Na nossa família somos um povo muito unido: filho, nora, irmão, irmã. O nosso povo Kokama está muito unido.

Até hoje nós somos discriminados, sim, ainda não parou. A discriminação continua: na educação, na saúde... O novo governo que tem hoje não nos ajuda em nada. Quer tirar o que nós temos ainda, a nossa pequena terra.

Entrevistamos também a líder indígena Maria, do povo Karapana. Maria é professora numa escola indígena onde leciona nheengatu:

A nossa atividade econômica, desde que eu nasci, sempre foi agricultura. Não era muito comércio, era mais troca. Trocava alimento perecível por um material que podíamos trocar naquela época. Só agricultura mesmo, através de roçado, da pesca, da coleta na floresta. Atualmente eu estou como professora de língua indígena.

Se eu não for um cidadão comum, e continuar sendo indígena, eu vou estar perdendo muita coisa. Eles querem que a gente esqueça a nossa identidade, e através disso, eles conseguem sobrepor os poderes deles sobre a nação indígena. Através da discriminação, através das perseguições, através da destruição dos nossos materiais, do nosso território, da nossa identidade. Eles tentam fazer isso de forma violenta, pressão psicológica, muitas coisas que eles buscam em parceria com o nosso Estado.

\section{Quarta e última etapa: o observatório ATTO, no meio da Selva}

A partir de Manaus, os dois viajantes foram explorar o interior da Amazônia ocidental. Enquanto Spix subiu pelo rio Solimões até Tabatinga e, depois, pelo Rio Negro até Barcelos - Martius foi estudar as tribos indígenas no rio Japurá, até a cachoeira de Araracoara, já em terras da Colômbia. Em vista da atualidade das questões climáticas e de preservação ambiental, nós decidimos conhecer o interior da Selva Amazônica por meio de uma ida ao Observatório ATTO (Amazon Tall Tower Observatory), uma estação de cooperação científica entre Brasil e Alemanha, situada a cerca de $160 \mathrm{~km}$ a nordeste de Manaus. Para chegar lá, fomos de carro pela BR-174 até Presidente Figueiredo, pegando depois a rodovia AM-240. Passando ao sul da represa de Balbina, chegamos no rio Uatumã. Embarcamos no Porto da Morena e descemos pelo rio. Fomos visitar uma comunidade ribeirinha: a de Maracarana. O presidente, o sr. Claudionor, nos apresentou o perfil da comunidade:

Nós chegamos aqui em 1980. Nós viemos todos juntos, lá do Baixo Amazonas. Habitantes aqui nós temos 42 famílias. Se for contar todos os adultos e todas as crianças, dá quase 300 pessoas. 
A nossa cultura aqui é essa: é roça, melancia. Quando é 4 horas da tarde, eu vou para a beira do rio e pego um peixe fresquinho. Não tem coisa melhor. Colheita nós fazemos. Temos aqui a reserva, uma reserva sustentável.

Temos uma escola, graças a Deus, para as nossas crianças. Quando elas saem daqui para fora, já é para passar para outro grau. Nós temos aqui um ensino muito bom em Maracarana.

Em seguida fomos ao porto do Observatório ATTO e subimos pela estrada de terra uns $15 \mathrm{~km}$ até o Campus, no meio da Selva. Ele dispõe de uma cozinha, refeitório e dormitório bem-organizados, e ali permanecemos durante quatro dias. Sobre o projeto ATTO, o meteorologista Stefan Wolff explicou:

O projeto ATTO foi construído mais ou menos uns 10 anos atrás. A ideia surgiu em 2007/2008, com o objetivo de entender melhor a relação entre uma floresta natural, tropical, equatorial e a atmosfera. O assunto da mudança climática é sempre um grande aspecto para a nossa pesquisa.

Os resultados da pesquisa servem para a sociedade, para entender melhor o papel importante da Amazônia para a região, para o continente, para o mundo inteiro. Temos um transporte, em alguns meses do ano, do norte da África, do deserto do Saara, que traz uma certa quantidade de areia do Saara para o sistema aqui da Amazônia. Esse transporte de areia até pode funcionar como uma certa fertilização do solo da Amazônia com vários minerais que não estão presentes aqui.

Hoje em dia, em relação a essa ciência, na qual a gente trata de certos assuntos no sistema terrestre, a gente trabalha com várias colaborações. Então, disciplinas tradicionais como a biologia, a química, a meteorologia, não podem ser colocadas isoladamente nesse projeto.

A gente instalou também um projeto de colaboração com as escolas aqui nos municípios. ${ }^{8}$

Caminhando pelas trilhas nos arredores do Campus, fomos conhecer animais da floresta como lagartos, cotias, borboletas e gaviões, e diversos tipos de plantas. A bióloga Altaíse nos falou de sua pesquisa de campo:

O meu trabalho está relacionado à fenologia. Como o clima influencia o funcionamento das plantas.

A fenologia está relacionada às fenofases, que são as mudanças fenológicas que vão ocorrendo com as plantas ao longo do ano. Por exemplo, a troca foliar.

Os modelos não podem considerar a floresta como sempre verde, como se fosse um tapete. A floresta não se comporta dessa maneira. Ela não é homogênea como a gente pensa.

Tem teorias que dizem: A Amazônia vai virar savana.

Uma das grandes dificuldades está nos dados de fenologia, que é o funcionamento das plantas frente às mudanças climáticas.

\footnotetext{
${ }^{8}$ Ver também o artigo de Stefan Wolff, "O projeto ATTO no coração da Amazônia: a história, a importância para a pesquisa e um olhar para o futuro", Martius-Staden-Jahrbuch, n. 63 (2020), p. 57-72.
} 
A Torre ATTO, com 325 metros de altura, é a torre mais alta de pesquisa no mundo. Na sua base tem um laboratório, onde trabalha a climatologista Bruna. Ela explica:

\begin{abstract}
A Amazônia é um lugar estratégico para entender como as emissões antropogênicas afetam o ecossistema amazônico.

Aqui no contêiner a gente tem um grupo de equipamentos para medir as diferentes propriedades dos aerossóis, desde concentração, tamanho, composição química. Isso é importante para entender quão bons são os aerossóis para a formação de nuvens, para ativar com gotas as nuvens. Esse tipo de propriedades dos aerossóis a gente estuda aqui.
\end{abstract}

O ponto mais alto da nossa estadia no Observatório, no sentido próprio da palavra, foi a subida até o topo da Torre. Lá em cima fomos presenteados com uma vista esplêndida sobre a Floresta Amazônica intacta, com o rio Uatumã no meio - a mais bela conclusão possível da nossa viagem na trilha de Spix e Martius. 200 anos atrás, os dois naturalistas recomendaram que o Brasil encontrasse um equilíbrio entre o avanço do progresso econômico-tecnológico e a preservação do meio ambiente. Na nossa memória ecoaram então as falas das pessoas que entrevistamos ao longo do percurso.

Um coro de múltiplas vozes, desde as histórias, lendas e mitos até as explicações dos cientistas, criando um diálogo entre os pesquisadores do ecossistema, do clima e das plantas com os depoimentos de trabalhadores braçais e vendedoras, que vivem dos produtos da floresta. Nos lembramos também das queixas dos indígenas, que continuam sendo discriminados e têm suas terras ameaçadas; e dos habitantes nas periferias das cidades, que são marginalizados pelo sistema, com a persistência das grandes desigualdades sociais. O que ouvimos e observamos nas comunidades ribeirinhas confirmou o fato de que os povos da Amazônia sobrevivem da floresta e que ela precisa ficar em pé. Essas comunidades valorizam também a educação, criando escolas de ensino fundamental para que os jovens possam continuar seus estudos nas cidades e abrir um diálogo entre saberes locais e pesquisas científicas. As entrevistas feitas em Manaus nos mostraram que na Amazônia é perfeitamente viável uma coexistência entre investimentos em atividades no polo industrial e a continuidade dos trabalhos tradicionais cuja base de sustento é a floresta.

Esses fatores criam uma perspectiva de esperança para a Região Amazônica no tempo atual, em que se intensificaram a destruição da floresta e a discriminação da 
população tradicional. Fazemos votos que essa esperança se confirme no futuro, para o bem dos povos da Amazônia.

\section{Referências}

AMARAL, José Ribeiro do. Fundação de Belém do Pará: jornada de Francisco Caldeira de Castelo Branco, em 1616. Brasília: Edições do Senado Federal, 2004 [1ª ed. 1916].

BARROS, Eloísa Amorim de; SILVA JR., Augusto Rodrigues da. "Raizamas do Brasil: benzeções amazônidas no oeste do Pará”. Martius-Staden-Jahrbuch, n. 63, p. 176-188, 2000.

BOLLE, Willi. Boca do Amazonas: sociedade e cultura em Dalcídio Jurandir, São Paulo: Edições do SESC, 2020.

CASTRO, Edna; MOURA, Edila; SÁ MAIA, Maria Lúcia (orgs.). Industrialização e Grandes Projetos: desorganização e reorganização do espaço. Belém: EdUFPA, 1995.

DI PAOLO, Pasquale. Cabanagem: a revolução popular da Amazônia. 3. ed. Belém: CEJUP, 1990.

FIGUEIREDO, Aguinaldo Nascimento. História do Amazonas. Manaus: Ed. Valer, 2011.

HUMBOLDT, Alexander von. Relation historique du Voyage aux Régions équinoxiales du Nouveau Continent. 3 vols. Ed. org. por Hanno Beck. Stuttgart: Brockhaus, 1980 [Reimpressão da edição original de 1814-1825].

JURANDIR, Dalcídio. Belém do Grão-Pará. 4. ed. Belém: Marques, 2016.

KOCH-GRÜNBERG, Theodor. Dois anos entre os indígenas: viagens ao noroeste do Brasil (1903/1905). Manaus: EdUA; FSDB, 2005.

KUPFER, Eckhard E. "Amazônia: do cacau à borracha, da borracha à alta tecnologia", In: BOLLE, Willi; CASTRO, Edna; VEJMELKA, Marcel (orgs.). Amazônia: região universal e teatro do mundo. São Paulo: Globo, 2010. p. 185-205.

MELO, Regina. Ykamiabas: filhas da Lua, mulheres da Terra. Manaus: Ed. Travessia, 2006.

MONTEIRO, Mário Ypiranga. Teatro Amazonas. 2. ed. Manaus: Ed. Valer; Governo do Estado do Amazonas, 2003.

MOURA, Carlos Eugênio Marcondes de. O teatro que o povo cria. Belém: Secult, 1997.

NIMUENDAJÚ, Curt. The Tukuna. Ed. org. por Robert Lowie. Berkeley: University of California Press, 1952. 
REIS, Arthur Cezar Ferreira. História de Óbidos. 2. ed. Rio de Janeiro: Civilização Brasileira, 1979.

SANJAD, Nelson. A Coruja de Minerva: o Museu Paraense entre o Império e a República (1866-1907). Brasília: Instituto Brasileiro de Museus; Belém: Museu Paraense Emílio Goeldi; Rio de Janeiro: Fundação Oswaldo Cruz, 2010.

SARGES, Maria de Nazaré. Belém: riquezas produzindo a Belle Époque. 3. ed. Belém: Paka Tatu, 2010.

SOUZA, Márcio. História da Amazônia. Manaus: Valer, 2009.

SPIX, Joh. Bapt. von; MARTIUS, Carl Friedr. Phil. von. Reise in Brasilien in den Jahren 1817 - 1820. 3 vols. Ed. org. por Karl Mägdefrau. Stuttgart: Brockhaus, 1980 [Reimpressão da edição original de 1823-1831].

. "Atlas" ou Tafelband [ = vol. IV de Reise in Brasilien in den Jahren 1817-1820].

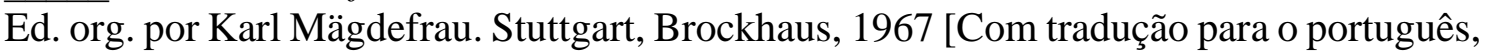
revisada por Helmut Sick].

Viagem pelo Brasil, 1817-1820. 3 vols. Tradução: Lúcia Furquim Lahmeyer. Brasília: Edições do Senado Federal, 2017.

STEINEN, Karl von den. Entre os aborígenes do Brasil Central. São Paulo: Departamento de Cultura, 1940.

TORRES, Maurício (org.). Amazônia revelada: Os descaminhos ao longo da BR-163. Brasília: CNPq, 2005.

WOLFF, Stefan. O projeto ATTO no coração da Amazônia: a história, a importância para a pesquisa e um olhar para o futuro. Martius-Staden-Jahrbuch, n. 63, p. 57-72, 2000.

\section{Documento eletrônico}

Filme documentário "Refazendo a viagem de Spix e Martius pela Amazônia" (48 min.): https://youtu.be/_eqyjKfd3z0. Acesso em 08/04/2021.

Artigo recebido em 04 de maio de 2021. Aprovado em 12 de julho de 2021. 